\title{
A review on the involvement of catecholamines in animal behaviour
}

\author{
H.A. O'Neill \\ Department of Animal, Wildlife and Grassland Sciences, University of the Free State, \\ Bloemfontein, 9300, South Africa
}

(Received 26 August 2018; Accepted 27 November 2018; First published online 2 March 2019)

Copyright resides with the authors in terms of the Creative Commons Attribution 4.0 South African Licence.
See: http://creativecommons.org/licenses/by/4.0/za
Condition of use: The user may copy, distribute, transmit and adapt the work, but must recognise the authors and the South African
Journal of Animal Science.

\begin{abstract}
Animal temperament and individual animal personalities in combination with an animal's ability to cope with stressful situations have been studied in the past. There are clear differences between cattle breeds in urinary catecholamine concentration. Individual differences in behaviour exist in a large number of species and breeds within species. This review gives an overview of the involvement of catecholamines in the expression of stress in animals. Domestication, the heritability of stress and terms currently used in animal personality research are discussed. This includes animals used for production. The aim of this review is to consolidate and present current knowledge on the function of an activated catecholamine system and to question whether behavioural changes of animals are tending towards increased aggressiveness or towards improved coping mechanisms.
\end{abstract}

Keywords: Animal welfare, domestication, fear, personality, stress

\# Corresponding author: oneillha@ufs.ac.za

\section{Introduction}

In the past, selection of animals in the livestock industry relied heavily on certain production traits. More recently, temperament has been considered to a greater extent in calculating breeding indexes. In beef and dairy cattle, heritability in temperament scores is high for flight speed, followed by docility and chute score, which is moderately heritable (Van Oers et al., 2004; Haskell et al., 2014). Aggression is also highly heritable in pigs (d'Eath et al., 2009), but selection against aggressive behaviour is not as simple as it seems. In pigs and in cattle, aggressive conduct towards the handler is often related to increased maternal behaviour (Haskell et al., 2014), which is a positive trait in mothering ability.

Research on animal stress and temperament is aimed at improvement in animal welfare (Disanto et al., 2014), in production potential (Burdick et al., 2010) and in product quality (Grandin, 2009; Muchenje et al., 2009). It seems that animal temperament, the way in which an animal expresses fear, and individual animal personalities are not clearly defined, which leads to confusion in interpretation. Various hormonal responses - such as catecholamine concentrations - have been measured to understand the hormonal regulation of a stress response, but with contradictory results. Understanding the term 'stress response' in animals is complicated by the findings of Finkemeier (2018), who showed that there are individual differences in behaviour in many species, including livestock. This review gives an overview of the involvement of catecholamines in the expression of stress in animals, and the heritability of catecholamine synthesis, and how it relates to domestication. Terms that are currently used in animal personality research are discussed.

\section{Evaluation of temperament scores}

An animal's tameness towards humans and its associated ease of handling are important aspects of the domestic phenotype (Price, 1999). In the past, temperament was defined as the fear response of cattle towards human handling (Fordyce et al., 1985; Petherick et al., 2003). Temperament scores are calculated as the animal's flight speed or exit velocity from a crush (Boles et al., 2015). Flight speed is measured as the 
amount of time it takes an animal to cover $1.7 \mathrm{~m}$ after leaving a crush. Animals with a slow flight speed are classified as tame (with a better temperament) and attain lower temperament scores (Fordyce et al., 1988).

The temperament of production animals has a direct effect on the economic return to a producer. It has an effect on growth rate, irrespective of production system. Better temperament scores of animals in feedlots correlate with higher growth rates in comparison with animals with poor temperaments (Fordyce et al., 1988; Hammond et al., 1998). Interestingly, these observations were made regardless of whether favourable scores resulted from intensive long-term handling or from animals that were naturally docile. Similarly, there was a relationship between growth rate and temperament in Bos taurus steers and heifers that grazed on pasture (Burrow \& Dillon, 1997). Cafe et al. (2011) found that cattle with more excitable temperaments (as measured by exit velocities) had consistently lower feed intake and slower growth rates, resulting in smaller carcasses.

In addition to growth rate, animal temperament influences the dressing percentage of meat-producing animals. Bos indicus-type cattle are perceived as less docile than Bos taurus types. According to Burrow \& Dillon (1997), bruise trim per carcass rises by about $0.3 \mathrm{~kg}$ per unit increase in temperament score. Carcasses from aggressive or temperamental cattle that were transported display more bruises along the back and around the tuber coxae and tuber ischii areas (Fordyce et al., 1988).

In addition to poor growth performance and lower dressing percentages, ante-mortem stress can have a negative effect on meat quality attributes. Animals with poor temperament scores have tougher meat and animals with better temperament scores are not only easier to handle, but obtain better meat tenderness values (Fordyce et al., 1988; Voisinet et al., 1997; Cafe et al., 2011). The relationship between excitable temperaments and higher shear force values is stronger in Bos indicus than in Bos taurus breeds (Voisinet et al., 1997; Cafe et al., 2011). From all these findings it is clear why researchers and producers often study animal temperament.

\section{Discovery and functions of catecholamines}

Almost a century ago, researchers became interested in the study of 'stress hormones', the involvement of these hormones in metabolism and the ways in which they influence behaviour. Many researchers (Cannon, 1929; Goldstein, 1995; Goldstein, 2003; Kvetnansky et al., 2009; Muchenje et al., 2009; O'Neill et al., 2012; 2016; 2018) have reported on the biochemical pathways and how catecholamines are involved in the expression of stress and fear. Cannon (1926) introduced the term 'fight or flight'. Selye (1936) defined stress as 'a nonspecific response of the body to any demand imposed upon it', and Goldstein (1995) explained that a stress response has a primitive kind of specificity.

The biological effects of catecholamines are mediated by two classes of trans-membrane receptors, namely $\alpha$ - and $\beta$-adrenoreceptors (also known as adrenergic receptors). An agonist is a substance that binds to a hormone receptor to trigger a hormonal response. An antagonist is a substance that binds to a hormone receptor, but fails to elicit a hormonal response and blocks any agonist action (Voet \& Voet, 1990). $\alpha-$ and $\beta$-adrenoreceptors, which occur on separate tissues in mammals, generally respond differently and often oppositely from catecholamines (Voet \& Voet, 1990).

Stimulation of $\alpha$-adrenoreceptors by $\alpha$-agonists causes intracellular effects that are mediated by the inhibition of adenylate cyclase ( $\alpha 2$ receptors) or via the phosphoinositide cascade ( $\alpha 1$ receptors). This leads to the stimulation of smooth muscle contraction in blood vessels that supply peripheral organs such as skin and kidney, smooth muscle relaxation in the gastrointestinal tract and blood platelet aggregation. Stimulation of $\beta$-adrenoreceptors by $\beta$-agonists activates adenylate cyclase which leads to increased glycogenolysis and gluconeogenesis in liver and skeletal muscle, increased lipolysis in adipose tissue, smooth muscle relaxation in the bronchi and blood vessels that supply the skeletal muscles, and increased heart rate. Most effects are directed towards a common end: the mobilization of energy resources and their shunting to where they are most needed to prepare the body for sudden action (Voet \& Voet, 1990).

Stress experienced by livestock is an inevitable result of transport, handling, feed withdrawal and mixing of animals from unfamiliar groups (Warriss, 1990; Apple et al., 2005; O'Neill et al., 2018).

Measuring circulating catecholamines or catecholamines in the urine or the brain will not give a clear indication of stress, fear or temperament. In some scientific communities, catecholamines are referred to as coping hormones as these hormones provide energy to the brain and a deficiency may lead to 'energy deficiency syndromes' in the brain (Todd \& Botteron, 2001). Catecholamine deficiency and hyperactivity have been indicated in human beings. In humans, dysfunctional catecholaminergic neurotransmitter systems contribute to the symptoms of attention deficit hyperactivity disorder (ADHD) (Sontag et al., 2010). The use of animal models for ADHD was evaluated and validated by Mefford \& Potter (1989) and Pliszka et al. (1996). Arnsten et al. (1996) emphasized the role of norepinephrine in focusing on stimuli or tasks. In a study by Sirvio et al. (1993) agents that increased brain norepinephrine improved attention in rats. 
Increased blood flow to the brain as a result of the activation of the catecholamine system makes an animal more able to cope with stressful situations (Sontag et al., 2010). The mechanisms that involve norepinephrine and corticotrophin-releasing factor act in tandem in such a way that norepinephrine systems regulate the release of brain corticotrophin-releasing factor via a a1-adrenoreceptor (Clark et al., 1988).

\section{Activation of the catecholamine system Acute stress}

The two central integrated processes, namely the autonomic nervous system and hypothalamicpituitary-adrenal axis, are activated as neuroendocrine responses to fear-eliciting stimuli. Acute stressors, such as human contact, activate an autonomic response to initiate a reaction that requires a rapid response. By activating the autonomic nervous system, tachycardia, increased respiration rate, elevated body temperature and redistribution of visceral blood volume towards skeletal muscle and the brain are some of the physiological changes that occur. The sympatho-adrenal component of the autonomic response is mediated by catecholamines - epinephrine and norepinephrine. Activation of the hypothalamic-pituitaryadrenal axis is manifested by the release of glucocorticoids from the adrenal cortex, and operates independently of stressful situations (Ferguson \& Warner, 2008).

If an animal is stressed through transport and handling, there is a quick release of catecholamines, which leads to changes in the carbohydrate metabolism to provide glucose for important functions (Lacourt \& Tarrant, 1985) and to assist an animal to cope with adverse situations. The catecholamine-induced effects on glucose homeostasis were termed by (Barth et al., 2007) - catecholamine infusion under physiological conditions is associated with enhanced rates of aerobic glycolysis, adenosine triphosphate (ATP) production, and glucose released from glycogenolysis and gluconeogenesis.

Dopamine is a catecholamine that is secreted under stressful situations. Intermittent tail-shock stress in mice increases extracellular dopamine relative to baseline values and it is concluded that dopamine concentration increases during adverse conditions (Abercrombie et al., 2006). Dopamine is involved in an animal's attraction to a stimulus that predicts reward (Lacourt \& Tarrant, 1985) and is involved in gluconeogenesis (Matsumura et al., 1980). O'Neill (2016) showed that cattle breed types differ in terms of dopamine secretion. Simmental breed types had significantly higher dopamine levels compared with Nguni and Brahman types. Dopamine helps to guide an animal towards objects in the environment that provide food and warmth and away from dangerous objects or environments (Parkinson et al., 2002). This strengthens the idea that catecholamines should be classified as coping hormones.

\section{Hunger}

During periods of feed withdrawal, plasma-free fatty acid concentration increases because fat reserves are mobilized to supply the animal with its energy requirements. Ferguson \& Warner (2008) stated that the need for energy is basic and animals in transit may experience hunger. The inability of an animal to resolve this state may invoke further psychological distress (Ferguson \& Warner, 2008). Catecholamine secretion results in significant changes in energy metabolism, including lipolysis, glycogenolysis in muscle and gluconeogenesis. Epinephrine is an effective initiator of glycogenolysis. It mediates glycolysis through a series of biochemical changes that amplify the cyclic adenosine monophosphate-mediated pathway. In this way, epinephrine activates vast amounts of phosphorylase rapidly (Ylä-Ajos, 2006). The primary source of energy to the brain is blood-borne glucose (Todd \& Botteron, 2001) and therefore catecholamines are crucial in providing the brain with 'energy'. Exposure to mixing and transport with feed and water withdrawal increases the utilization and synthesis of dopamine, norepinephrine and epinephrine, which implies that with feed restriction there may be a shortage of catecholamines (Schaefer et al., 2001; O'Neill et al., 2018). When catecholamine synthesis is compromised through restricted feeding, animals become less resistant to stress. Under these conditions, animals cannot cope and develop an array of counterproductive behavioural (learned helplessness) changes. Stressed feed-restricted animals are unable to respond appropriately to stimuli. They are unable to function normally, and eating and sleeping patterns are disturbed (Anisman \& Zacharko, 1986 and Lieberman, 1994, cited in Schaefer et al., 2001).

O'Neill (2016) found that 24-hour feed withdrawal had no effect on urinary norepinephrine and epinephrine concentrations, but dopamine concentration was significantly lower when feed was withdrawn for 24 hours compared with three hours. The ratios of norepinephrine conversion to dopamine and epinephrine conversion to dopamine were significantly higher when feed was restricted for 24 hours.

\section{Transport and increased activity}

Animals that are transported may experience increased activity (Ferguson \& Warner, 2008). Contracting muscle needs glucose and ATP as energy source. The rate of glycogenolysis in resting living mammalian muscle is low. In contracting muscle, glycogenolysis is triggered by a cascade of activating 
glycogenolytic enzymes. This is initiated by, among others, increased catecholamine release, a subsequent increased calcium ion $\left(\mathrm{Ca}^{2+}\right)$ content in the cytosol or a combination of these processes (Tarrant, 1989; Spriet et al., 1990). At an early stage of exercise, muscle contraction stimulates glycogenolysis (Richter et al., 1981; 1982). Muscle contraction induces the conversion of inactive phosphorylase to the active form through an allosteric activation caused by $\mathrm{Ca}^{2+}$ release from the sarcoplasmic reticulum (Roach, 2002). This triggers immediate glycogen breakdown. Continued glycogenolysis needs the direct effect of epinephrine on muscle (Richter et al., 1982) or phosphorylase reverts to resting levels (Richter et al., 1982; Hespel \& Richter, 1992).

\section{Pain}

Norepinephrine is involved in the perception of pain by an animal. Pain sensitivity (beyond opioidergic control) decreases through descending noradrenergic pathways (Devor et al., 1984). The main role of norepinephrine release and the onset of a socially relevant stimulus is the establishment of somatic and neural conditions that ensure maximal efficiency in coping.

Rodriguez et al. (2018) used biomarkers and found variations in plasma concentrations of norepinephrine, substance $P$ and $\beta$-endorphin in a study in which pain through lameness in cows was investigated. Rodriguez et al. (2018) concluded that further studies should be done in this field to evaluate the potential use of biomarkers in the detection of chronic bovine painful conditions and the interaction between catecholamines and endorphins.

\section{The role of catecholamines in domestication}

Catecholamines plays a crucial role in an animal's ability to cope with stressful situations because selection for tameness results in increased catecholamine synthesis, which is linked to tamer and more domesticated animals. From the results of domestication studies, it was found that selection for tameness in foxes and rats influences the catecholamine system of the brain (Cuomo-Benzo et al., 1977; Price, 1999). Similarly, domestication of Sprague Dawley and Long Evans rats resulted in significant increments in norepinephrine and epinephrine content in whole brain (Cuomo-Benzo et al., 1977). In rats and foxes, selected tame animals had higher levels of norepinephrine in the hypothalamus than unselected non-tame control lines. Lower levels of norepinephrine were found in wild rats compared with domesticated rats. Researchers concluded that selection pressure favours high norepinephrine content in the domesticated rat and silver fox. This enables the domesticated rat to perform effectively in laboratory test situations (CuomoBenzo et al., 1977).

\section{Heritability and gene expression of catecholamine synthesis}

Catecholamine synthesis is inherited genetically as polymorphisms occur in the dopamine- $\beta$ hydroxylase gene (Kopeckova et al., 2006). Dopamine- $\beta$-hydroxylase is the enzyme that is responsible for the conversion of dopamine to norepinephrine and is released as a response to exposure to stressful situations. Dopamine- $\beta$-hydroxylase activity is derived largely from sympathetic nerves and is measured in human plasma. Polymorphisms occur frequently in the dopamine- $\beta$-hydroxylase gene, the G444A, G910T, C1603T, C1912T, C-1021T, 5'-ins/del and Taql (Kopeckova et al., 2006). These polymorphisms affect the function of gene products or modify gene expression, and thus influence the progression of ADHD (Kopeckova et al., 2006) and possibly animal temperament.

\section{Catecholamines are coping hormones}

In human studies, ADHD and over-reactivity have been ascribed to catecholamine shortages, with subsequent lower blood flow to the brain, coupled with lower gluconeogenesis (Todd \& Botteron, 2001). Human subjects with this disorder were unable to cope with challenging environments. Clearly catecholamines are responsible for providing the brain with sufficient glucose to cope with environmental stimuli.

Galvin et al. (1995; 1997) measured decreased activities of dopamine- $\beta$-hydroxylase in serum and urine in patients with ADHD and concluded that low dopamine- $\beta$-hydroxylase levels correlate indirectly with the seriousness of the hyperkinetic syndrome in children (Galvin et al., 1995; 1997).

When animals experience acute stress through transport and handling, a quick release of catecholamines leads to changes in the carbohydrate metabolism to provide glucose for important functions and to aid an animal in coping with stressful situations. By activating the autonomic nervous system, tachycardia, increased respiration rate, elevated body temperature and redistribution of visceral blood volume towards skeletal muscle and the brain are some of the physiological changes that occur (Lacourt \& Tarrant, 1985). 
In stress research, 'coping' is defined as a set of behavioural and physiological characteristics of an individual that is trying to overcome the challenge of an adverse situation. In the animal kingdom, two coping patterns are distinguished: an 'active pattern' and a 'passive pattern' (Krause, 2017). Studies in fish and birds often use the terms 'shyness' and 'boldness' (Coleman et al., 1994). Despite domestication, targeted selection, genetic modification and inbreeding, the same coping strategies can be observed in laboratory and farm animals.

Studies focusing on coping styles in animals suggest that the 'active' response is characterized by a typical active fight-or-flight response in adverse situations. This is often associated with territorial control, aggression and risk taking (Cannon, 1929; Koolhaas et al., 1999). On the other hand, the 'passive' coping style shows a conservation withdrawal response in adverse situations. This is often recognized behaviourally by immobility and low levels of aggression (Engel \& Schmale, 1972). These two coping styles differ fundamentally in their general adaptive response patterns to challenges (Koolhaas et al., 1999), which leave unanswered many questions in the study of animal behaviour.

\section{Comparison of catecholamine concentration between cattle breeds}

Results from O'Neill (2016) indicate that ante-mortem urinary norepinephrine and epinephrine concentrations that are sampled from the bladders of cattle immediately after slaughter differ between breeds. Ante-mortem urinary catecholamines of Nguni cattle are higher than those of Brahman and Simmental. The conversion rates of dopamine to norepinephrine and dopamine to epinephrine differ significantly between breeds. For Brahman-type cattle the conversion rate of dopamine to norepinephrine and epinephrine is higher compared with Simmental-type cattle, and Nguni is intermediate between Brahman and Simmental (O'Neill, 2016). Since dopamine- $\beta$-hydroxylase is responsible for converting dopamine into norepinephrine and subsequently epinephrine, it may explain differences in catecholamine synthesis between Brahman, Nguni and Simmental. Simmental cattle have significantly higher dopamine levels compared with Nguni and Brahman (O'Neill, 2016). Aversive conditions (such as transport and handling at an abattoir) increase urinary dopamine, as described for other species by Abercrombie et al. (2006). Dopamine has been shown to be involved in gluconeogenesis (Matsumura et al., 1980) to make glucose available to an animal to cope with its environment. Dopamine is an important neurotransmitter, which is involved in an animal's attraction to a stimulus that predicts reward (Parkinson et al., 2002). This adaptive value helps to guide an animal towards objects in the environment that provide food and warmth and away from dangerous objects or environments. Simmental cattle may be more adaptive in the way that they seek rewarding stimuli.

Catecholamines have been implicated in the behaviour and domestication timeline of different animal species. From classic domestication studies with silver foxes (Nikulina, 1990) and rats (Price, 1999), animals with a possible longer history of domestication were tamer and showed higher levels of catecholamines in the central and peripheral nervous system. Results from domestication studies (Nikulina, 1990; Price, 1999) and research that indicated that Bos indicus breed types are more temperamental than Bos taurus types (Voisinet et al., 1997; O'Neill, 2016) emphasise the need for a paradigm shift in the traditional way of classifying catecholamines as purely 'stress hormones'. The involvement of catecholamines in cattle temperament should be considered because Nguni and Simmental showed higher levels of urinary catecholamines than the typically temperamental Brahman.

\section{The complexity of animal personality}

Finkemeier (2018) indicated the importance of investigating and understanding individual animal differences. Not only do breeds differ in catecholamine synthesis, but each animal exhibits its own personality and reacts differently to external stimuli (Finkemeier, 2018). This can be used as a possible means of measuring and improving states of welfare.

During domestication of livestock species, animal behaviour has changed to lower levels of aggression (Rauw et al., 2017). Rauw et al. (2017) uses the term 'reactive copers'. They reported that artificial selection by animal producers to improve production traits may have resulted indirectly in the selection of animals that count as reactive copers. Animal personality and an animal's expression of fear are not easily understood. For example, sudden changes in behaviour such as aggressiveness towards the handler may be an indication of pain or other problems (Fureix et al., 2008).

Adaptation to environment of individual animals plays a critical role in fear responsiveness. Animals that are not adapted to their environment may experience diminished welfare, which can lead to reduced productivity. Animal personality influences behaviour and physiology directly and therefore individual welfare. One should keep in mind that welfare, via a feedback loop, can influence behaviour and physiology directly. Especially in farm animals, domestication has an impact on behaviour and physiology and influences breeding directly (Finkemeier, 2018). 


\section{Conclusion}

The measurement of catecholamine concentration per se is not an indication of an animal's reactive behaviour towards a stressful stimulus. Domestication studies reveal that animals with longer domestication history are tamer, with genetically higher catecholamines in the system. The conversion of dopamine to norepinephrine and epinephrine is dependent on dopamine- $\beta$-hydroxylase, which is inherited genetically and is implicated in humans and the expression of ADHD and validated against animal models. Each animal exhibits its own unique personality and expresses fear differently. The terms 'coping style' and 'temperament', which are used in different ways, should not be examined as independent concepts. Farm animal personality should be increasingly considered to improve animal housing, management, breeding and welfare.

\section{Conflict of Interest Declaration}

The author declares that she has no conflict of interest.

\section{References}

Abercrombie, E.D., Keefe, K.A., DiFrischia, D.S. \& Zigmond, M.J., 2006. Differential effect of stress on in vivo dopamine release in striatum, nucleus accumbens, and medial frontal cortex. J. Neur. 52 (5), 1655-1658.

Anisman, H. \& Zacharko, R.M. 1986. Behavioural and neurochemical consequences associated with stressors. Annals of the New York Academy of Sciences 467, 205-225.

Apple, J.K., Kegley, E.B., Galloway, D.L., Wistuba, T.J. \& Rakes, L.K., 2005. Duration of restraint and isolation stress as a model to study the dark-cutting condition in cattle. J. Anim. Sci. 83, 1202-1214.

Arnsten, A.F., Steere, J.C. \& Hunt, R.D., 1996. The contribution of a2-noradrenergic mechanisms of prefrontal cortical cognitive function. Potential significance for attention-deficit hyperactivity disorder. Arch. Gen. Psychiat. 53, 448-455.

Barth, E., Albuszies, G. \& Baumgart, K., 2007. Glucose metabolism and catecholamines. Crit. Care. Med. 35, 508-518.

Boles, J.A., Kohlbeck, K.S., Meyers, M.C., Perz, K.A., Davis, K.C. \& Thomson, J.M., 2015. The use of blood lactate concentration as an indicator of temperament and its impact on growth rate and tenderness of steaks from Simmental x Angus steers. Meat Sci. 103, 68-74.

Burdick, N.C., Carroll, J.A., Hulbert, L.E., Dailey, J.W., Willard, S.T., Vann, R.C., Welsh Jr., T.H. \& Randel, R.D., 2010. Relationships between temperament and transportation with rectal temperature and serum concentrations of cortisol and epinephrine in bulls. Livest. Sci. 1, 129, 166-172.

Burrow, H.M. \& Dillon, R.D., 1997. Relationships between temperament and growth in a feedlot and commercial carcass traits of Bos indicus crossbreds. Aust. J. Exp. Agr. 37, 407-411.

Cafe, L.M., Robinson, D.L., Ferguson, D.M., Mclntyre, B.L., Geesink, G.H. \& Greenwood, P.L., 2011. Cattle temperament: Persistence of assessments and associations with productivity, efficiency, carcass and meat quality traits. J. Anim. Sci. 89, 1452-1465.

Cannon, W.B., 1929. Organization for physiological homeostasis. Physiological Reviews 9, 399-431.

Clark, C.R., Geffen, G.M. \& Geffen, L.B., 1988. Catecholamines and attention. I: Animal and clinical studies. Neurosci. Biobehav. R. 341-352.

Coleman, K. \& Wilson, D.S., 1998. Shyness and boldness in pumpkinseed sunfish: Individual differences are contextspecific. Anim. Behav. 56, 927-936. Doi: 10.1006/anbe.1998.0852.

Cuomo-benzo, M., Price, E.O. \& Hartenstein, R., 1977. Catecholamine levels in whole brain of stressed and control domestic and wild rats (Rattus norvegicus). Behav. Process. 2, 33-40.

d'Eath, R.B., Roehe, R., Turner, S.P., Ison, S.H., Farish, M., Jack, M.C. \& Lawrence, A.B., 2009. Genetics of animal temperament: aggressive behaviour at mixing is genetically associated with the response to handling in pigs. Animal 3, 1544-1554.

Devor, M., 1984. Pain and 'state'-induced analgesia: An introduction. In: M.D. Tricklebank \& G. Curzon. Stress-induced analgesia. Wiley, Chichester. 1-19.

Disanto, C., Celano, G., Varvara, M., Fusiello, N., Fransvea, A., Bozzo, G. \& Celano, G.V., 2014. Stress factors during cattle slaughter. Ital. J. Food. Saf. 3 (3), 143-144, Doi: 10.4081/ijfs.2014.1682.

Engel, G.L. \& Schmale, A.H., 1972. Conservation withdrawal: A primary regulatory process for organic homeostasis. Physiology, emotions and psychosomatic illness. Elsevier, New York. pp. 57-95.

Ferguson, D.M. \& Warner, R.D., 2008. Have we underestimated the impact of pre-slaughter stress on meat quality in ruminants? Meat Sci. 80, 12-19.

Finkemeier, M.A., Langbein, J. \& Puppe, B., 2018. Personality research in mammalian farm animals: Concepts, measures, and relationship to welfare. Front. Vet. Sci. 5, Doi: 10.3389/fvets.2018.00131.

Fordyce, G., Goddard, M.E., Tyler, R., Williams, G. \& Toleman, M.A., 1985. Temperament and bruising of Bos indicus cross cattle. Aust. J. Exp. Agr. 25, 283-288.

Fordyce, G., Wythes, J.R., Shorthose, W.R., Underwood, D.W. \& Shepherd, R.K., 1988. Cattle temperament in extensive beef herds in northern Queensland. 2. Effect of temperament on carcass and meat. Aust. J. Exp. Agr. 28, 689-693.

Fureix, C., Menguy, H. \& Hausberger. M., 2008. Partners with bad temper: Reject or cure? A study of chronic pain and aggression in horses. PLoS ONE. 5:e12434. Doi: 10.1371/journal.pone.0012434 
Galvin, M., Teneyck, R., Shekhar, A., Stilwell, B., Fineberg, N., Laite, G. \& Karwisch, G., 1995. Serum dopamine- $\beta$ hydroxylase and maltreatment in psychiatrically hospitalized boys. Child Abuse \& Neglect 19, 821-832.

Galvin, M., Stilwell, B.M., Shekhar, R., Kopta, S.M. \& Goldfarb, S.M., 1997. Maltreatment, conscience functioning and dopamine- $\beta$-hydroxylase in emotionally disturbed boys. Child Abuse \& Neglect 21, 83-92.

Goldstein, D.S., Swoboda, K.J., Miles, J.M., Coppack, S.W., Aneman, A., Holmes, C., Lamensdorf, I. \& Eisenhofer, G., 1999. Sources and physiological significance of plasma Dopamine sulphate. J. Clin. Endocr. Metab. 84, 2523-2531.

Goldstein, D.S. \& Kopin, I.J., 2007. Evolution of concepts of stress. Stress 10, 109-120.

Grandin, T., 2013. Evaluation of methods of restraint for holding (fixation) of cattle, calves, and sheep for kosher and halal slaughter (unpublished).

Hammond, A.C., Chase Jr., C.C., Bowers E.J., Olson, T.A. \& Randel, R.D., 1998. Heat tolerance in Tuli-, Senepol-, and Brahman-sired F1 Angus heifers in Florida. J. Anim. Sci. 76, 1568-1577.

Haskell, M.J., Simm, G. \& Turner, S.P., 2014. Genetic selection for temperament traits in dairy and beef cattle. Front. Genet. 5, 368, Doi: 10.3389/fgene.2014.00368.

Hespel, P. \& Richter, E.A., 1992. Mechanism linking glycogen concentration and glycogenolytic rate in perfused contracting rat skeletal muscle. Biochem. J. 284 (3), 777-780.

Koolhaas, J.M., Korte, S.M., De Boer, S.F., Van Der Vegt, B.J., Van Reenen, C.G. \& Hopster, H., 1999. Coping styles in animals: Current status in behaviour and stress-physiology. Neurosci. Biobehav R. 23, 925-935. Doi: 10.1016/S0149-7634(99)00026-3

Kopeckova, M., Palct, I. \& Goetz, P., 2006. Polymorphisms of dopamine- $\beta$-hydroxylase in ADHD children. Folia. Biol. Prague 52, 194-201.

Krause, A., Puppe, B. \& Langbein, J., 2017. Coping style modifies general and affective autonomic reactions of domestic pigs in different behavioural contexts. Front. Behav. Neurosci. 11, 103. Doi: 10.3389/fnbeh.2017.00103.

Kvetnansky, R., Sabban, E.L. \& Palkovits, M., 2009. Catecholaminergic systems in stress: Structural and molecular genetic approaches. Physiol. Rev. 89, 535-606.

Lacourt, A. \& Tarrant, P.V., 1985. Glycogen depletion patterns in myofibers of cattle during stress. Meat Sci. 15 (2), $85-100$

Matsumura, M., Akiyoshi, H. \& Saito, S., 1980. Effects of somatostatin on gastrointestinal hormone-induced glycogenolysis and gluconeogenesis in cultured liver cells. Gastroenterol. Jpn. 15 (5), 439-443.

Mefford, I.N. \& Potter, W.Z., 1989. A neuro-anatomical and biochemical basis for attention deficit disorder with hyperactivity in children: A defect in tonic adrenaline mediated inhibition of locus coeruleus stimulation. Med. Hypotheses 29, 33-42.

Meléndez-Hevia, E., Waddell, T.G. \& Shelton, E.D., 1993. Optimization of molecular design in the evolution of metabolism: The glycogen molecule. Biochem. J. 295, 477-483.

Muchenje, V., Dzama, K., Chimonyo, B., Strydom, P.E. \& Raats, J.G., 2009. Relationship between pre-slaughter stress responsiveness and beef quality in three cattle breeds. Meat Sci. 81, 653-657.

Nikulina, E.M., 1990. Brain catecholamines during domestication of the silver fox (Vulpes fulvus). J. Evol. Biochem. Physiol. 26, 118-121.

O'Neill, H.A., 2016. The influence of catecholamines on energy metabolism and selected meat quality attributes of three commercial beef breeds (doctoral dissertation, University of Pretoria, Pretoria).

O'Neill, H.A. \& Webb, E.C., 2012. The conversion of dopamine to epinephrine and nor-epinephrine is breed dependent. S. Afr. J. Anim. Sci. 4, 502-504.

O'Neill, H.A., Webb, E.C., Frylinck, L. \& Strydom, P.E., 2018. Effects of short and extended fasting periods and cattle breed on glycogenolysis, sarcomere shortening and Warner-Bratzler shear force. S. Afr. J. Anim. Sci. 48, 71-80.

Parkinson, J.A., Dalley, J.W., Cardinal, R.N., Bamford, A., Fehnert, B., Lachenal, G., Rudarakanchana, N., Halkerston, K.M., Robbins, T.W. \& Everitt, B.J., 2002. Research report: Nucleus accumbens Dopamine depletion impairs both acquisition and performance of appetitive Pavlovian approach behaviour: implications for mesoaccumbens Dopamine function. Behav. Brain Res. 137, 149-163.

Petherick, J.C., Holroyd, R.G. \& Swain, A.J., 2003. Performance of lot-fed Bos indicus steers exposed to aspects of a feedlot environment before lot-feeding. Aust. J. Exp. Agric. 43, 1181-1191.

Pliszka, S.R., McCracken, J.T. \& Maas, J.W., 1996. Catecholamines in attention-deficit hyperactivity disorder: current perspectives. J. Am. Acad. Child. Adolesc. Psychiatry 35, 264-272.

Price, E.O., 1999. Behavioural development in animals undergoing domestication. Appl. Anim. Behav. Sci. 65, $245-271$.

Rauw, W.M., Johnson, A.K., Gomez-Raya, L. \& Dekkers, J.C.M., 2017. A hypothesis and review of the relationship between selection for improved production efficiency, coping behaviour and domestication. Front. Genet. 8 (134). Doi: $10.3389 /$ fgene.2017.00134

Richter, E.A., Galbo, H. \& Christensen, N.J., 1981. Control of exercise-induced muscular glycogenolysis by adrenal medullary hormones in rats. J. Appl. Physiol. Respir. Environ. Exerc. Physiol. 50, 21-26.

Richter, E.A., Ruderman, N.B., Gavras, H., Belur, E.R. \& Galbo, H., 1982. Muscle glycogenolysis during exercise: dual control by epinephrine and contractions. Am. J. Physiol. 242, E25-E32.

Roach, P.J. 2002. Glycogen and its metabolism. Curr. Mol. Med. 2 (2), 101-120.

Rodriguez, A., Herzberg, D., Werner, M., Müller, H. \& Bustamante, H., 2018. Plasma concentration of norepinephrine, $\beta$ endorphin, and substance $P$ in lame dairy cows, J. Vet. Res. 62, 193-197.

Schaefer, A.L., Dubeski, P.L., Aalhus, J.L. \& Tong, A.K.W., 2001. Role of nutrition in reducing ante mortem stress and meat quality aberrations. J. Anim. Sci. 79, E91-E101.

Selye, H., 1956. The Stress of Life. McGraw-Hill, New York, USA. 
Sirvio, J., Jakala, P., Mazurkiewicz, M., Haapalinna, A., Riekkinen, P. Jr. \& Riekkinen, P.J., 1993. Dose- and parameterdependent effects of atipamezole, an alpha 2-antagonist, on the performance of rats in a five-choice serial reaction time task. Pharmacol. Biochem. Be. 45, 123-129.

Sontag, T.A., Tucha, O., Walitza, S. \& Lange, K.W., 2010. Animal models of attention deficit / hyperactivity disorder (ADHD): A critical review. Atten. Defic. Hyperact. Disord. 2, 1-20.

Spriet, L.L., Bernadinucci, L., Marsh, D.R., Campbell, C.B. \& Graham, T.E., 1990. Glycogen content has no effect on skeletal muscle glycogenolysis during short-term tetanic stimulation. J. Appl. Physiol. Respir. Environ. Exerc. Physiol. 68, 1883-1888.

Tarrant, P.V., 1989. Animal behaviour and environment in the dark-cutting condition. In S.U. Fabiansson, W.R. Shorthose \& R.D. Warner (eds.), Dark-cutting in cattle and sheep. Proceedings of an Australian Workshop (pp. 8-18). Australian Meat and Livestock Research and Development Corporation.

Todd, R.D. \& Botteron, K.N., 2001. Review: Is attention-deficit/hyperactivity disorder an energy deficiency syndrome? Biol. Psychiat. 50, 151-158.

Van Oers, K., Drent, P.J., Jong, G.D. \& Noordwijk, A.J., 2004. Additive and nonadditive genetic variation in avian personality traits. Heredity $93,496-503$.

Voet, D. \& Voet, J.G., 1990. Biochemistry. John Wiley \& Sons, New York, USA.

Voisinet, B.D., Grandin, T., O'Connor, S.F., Tatum, J.D. \& Deesing, M.J., 1997. Bos indicus-cross feedlot cattle with excitable temperaments have tougher meat and a higher incidence of borderline dark cutters. Meat Sci. 46, 367-377.

Warriss, P.D., 1990. The handling of cattle pre-slaughter and its effects on carcass and meat quality. Appl. Anim. Behav. Sci. 28, 171-186.

Ylä-Ajos, M., 2006. Glycogen debranching enzyme activity in the muscles of meat producing animals. Academic dissertation, University of Helsinki, Finland. 